population gains its living, the plough and the waggon having given place to the net and the boat.

The reclamation of Lake Harlem having demonstrated the great advantages to be gained by such works, several schemes were subsequently brought forward for reclaiming the Zuiderzee and regaining what was thus stolen by the sea, the most extensive of these plans proposing the joining together of the islands which were left standing, and filling the gaps between them by embankments.

At last, in I894, a Commission of twenty-seven members was appointed by the Government to make a thorough investigation of the subject, the commissioners being selected for their special capabilities for determining as to the practicability of the reclamation from an engineering point of view, and as to the cost ; as to the adaptability of the land for agricultural purposes, and its value when reclaimed; as to the proper way of dealing with the interests of the fishermen who would be displaced; and generally the advantages that would occur to the State. This Commission reported in 1892 , and recently a Bill was brought before the Dutch States General for carrying into effect the recommendations of the commis sioners. Owing to a change in the Ministry the Bill lapsed before it had passed through the necessary stages, but there is no doubt that it will be revived in due course by the new Ministry.

The idea of entirely reclaiming the whole of the Zuiderzee by uniting the islands has been abandoned as commercially. impracticable, and a modified scheme adopted for only enclosing the inner portion by an embankment 18 miles in length, extending from the North Holland coast near the island of Wieringen to the Friesland coast near Piaam. The top of this embankment will require to be 18 feet above mean high water, and it is proposed to construct in it two locks and six outfall sluices, giving a total waterway of 984 feet for the discharge of the water from the River Ysell. One of the locks is to be of sufficient size for sea-going craft, which will thus be able to get to Amsterdam through the locks at Schellingwoude and to other parts of Holland along the various canals that now have communication with the Zuiderzee. On the top will run a road and railway. The estimated cost of this bank is $3,000,000$. When the bank is completed it is proposed to reclaim two large areas of land on the west side which are now covered by, water, containing together $131,45^{\circ}$ acres, of which I I 5,000 acres will be available for cultivation, the remainder being occupied by roads, drainage canals and banks. For the drainage of these reclaimed polders eight steam pumps will be required, of an aggregate capacity of $433^{\circ}$ horse-power.

Subsequently it is intended to reclaim two further tracts containing 365,288 acres, but this reclamation was not included in the Bill now under consideration. When this is done there will remain a large area of water, practically the site of Lake Flevo, covering 560 square miles. It is considered that the depth of the water in this lake is too great for profitable reclamation. The cost of enclosing the two tracts of land and providing the necessary pumping machinery is estimated at $2,962,500 l$. For the interests of the fishery $375,000 \mathrm{l}$. is allocated ; for military defences, $666,000 l$; for deepening the approaches to the harbours and other works in the interests of the navigation, 7 I7,000l., making, with the cost of the bank, a total estimated cost of $7,720,500 l$. The enclosure of the eastern polders, containing 365,288 acres of cultivatable land, is estimated at $7,862,500 l$., making a grand total of $15,583,000 l$.

The enclosing dyke is reckoned to occupy nine years ; the reclamation of the western polders would be completed at the end of fourteen years, and it would take thirty-three years before the whole reclamation could be completed.

It is proposed that the cost of the works, amounting NO. I 682 , VOL. 65$]$ to $7,720,500 l$., shall be repaid by annual instalments spread over sixty years, requiring an annual charge of $166,667 l$. The renting value of the reclaimed land is estimated at $230,000 l$. a year, showing an annual financial gain of 63,333 l.

It is considered that, even if no financial gain should ensue, the scheme is one that will be of eminent advantage in the increase in the general prosperity:-by creating a better condition of the Waterstaat over a considerable portion of the country, and in effecting a large saving in the cost at present incurred in pumping and in the maintenance of the sea banks, the length of which will be reduced from 198 to 25 miles; by the establishment of direct communication by road and railway along the new bank between North Holland and Friesland, which will shorten the distance between Leuwarden and Amsterdam 35 miles; and, above all, by the economic advantages that will be derived from the cultivation of a very extensive tract of land, and the employment that will be given to a very large population W. H. WHEELER.

\section{SMALL-POX IN LONDON.}

THE statistical committee of the Metropolitan Asylums Board has recently presented an interesting report upon the cases of small-pox which have been treated by the Board during the year Igor. This report enables us to trace the growth of the present epidemic, and, so far as it goes, dealing with IOI7 cases of smallpox, teaches us some very useful lessons upon a subject at the present time of the most profound interest, viz., the efficacy of vaccination as a protective measure.

It appears that in the early part of last year, in fact up to August, London was unusually free from small-pox, only slightly more than a dozen cases having occurred. From August 22 and on, however, the disease appeared to have obtained a strong hold in the parishes of St. Marylebone and St. Pancras. Subsequently cases occurred in every one of the thirty-one poor-law parishes and unions comprising the Metropolitan Asylum District. The average weekly admissions were as follows:-In August, $35^{\circ} 5$, September, $37^{\circ} 75$; October, $39^{\circ} 75$; November, I I 3.6 December I to 28,1645 ; December 28 to January 4 $242^{\circ} \mathrm{O}$.

With regard to gross mortality, this is given at 2428 per cent. It must, however, be borne in mind that in arriving at this figure many cases of recent admissions have been included because they have already been completed by death, whereas the contemporary cases, which will probably nearly all recover ultimately, cannot be included until completed by discharge. The result is that the rate of mortality above must be admitted to be undoubtedly higher than it will be when all the cases have been completed and the final rate ascertained.

For the purpose of estimating the effect of vaccination upon the cases which have died or recovered during the year, these were divided into three classes: (I) cases with visible cicatrices, (2) doubtful cases, (3) unvaccinated cases. The total mortality rate per cent. of vaccinated cases was I 4.21 ; of doubtful cases $65^{\circ} 08$; of unvaccinated cases $50^{\circ} 52$. It strikes one at first as odd that the mortality of the doubtful cases was ten per cent. higher than that of the admittedly unvaccinated. By definition it, however, appears that the doubtful cases most probably consisted of practically unvaccinated cases, and were very few in number. Perhaps one of the most marked features in these statistics is the protection from smallpox afforded by successful infantile vaccination. Under ten years of age only twelve vaccinated cases are recorded and no death. Infantile vaccination, further, seemed greatly to diminish the rate of mortality from the disease even up to forty, although there was a very rapid 
falling off of its power in this direction after twenty years of age.

With regard to the value of and necessity for revaccination, the experience of the committee confirms that of a similar committee which reported upon the smallpox epidemic of $1870-72$. "No greater argument to prove the efficacy of this precaution," says this report, "can be adduced than the fact that out of upwards of 14,000 cases received into the hospitals only four wellauthenticated ones were treated, in which revaccination had been properly performed, and these were slight attacks."

\section{NOTES}

THE work of preparing Bushy House for the National Physical Laboratory is now approaching completion, and, His Royal Highness the Prince of Wales has fixed Wednesday, March 19, for the opening ceremony. The object of the Laboratory is to encourage the applications of physical science to manufactures and industry. This it will do by undertaking researches into questions of importance to either, and by testing apparatus and material used in trade.

Prof. J. W. Gregory, F.R.S., has been temporarily appointed head of the Geological Survey of Victoria, with a view to its complete reorganisation and the substitution of a staff engaged on a permanent basis instead of the present temporary plan. The Victorian Government is paying for extra assistance in the geological department of the University while Prof. Gregory is engaged upon this work.

AN expedition to Lake Eyre, the great depression in Central Australia sinking below sea-level, has recently left Melbourne. The party consists of Prof. J. W. Gregory, his assistant, Mr. H. J. Grayson, and five studentsy of the geological department of the Melbourne University. The main objects of the expedition are the study of the physical history of the Lake Eyre basin and the collection of fossils, especially the extinct giant vertebrates. The camel caravan starts from Hergott Springs, a station 440 miles north of Adelaide. It is hoped that the collections will throw light on some unexplained native traditions as to former giant animals that inhabited the Lake Eyre basin.

THE annual congress of the Sanitary Institute will be held in Manchester on September 9-13, when Earl Egerton of Tatton will preside. Section I. (Sanitary Science and Preventive Medicine) will be presided over by Sir J. Crichton Browne, F.R.S.; Section II. (Engineering and Architecture) by Sir Alexander Binnie; and Section III. (Physics, Chemistry and Biology) by Prof. A. Sheridan. Delpéine. Eight technical conferences will also be held in connection with the congress.

In the House of Commons on Monday, in reply to Mr. Field, who asked a question in regard to the proposed erection of a suitable College of Science in Dublin, Mr. Austen Chamberlain said :- "Thirteen thousand pounds was voted in I899-1900 and applied towards the purchase of part of the site for a new college. I hope shortly to introduce a Bill for the acquisition of the rest of the site, for the provision of funds for the new building, and other purposes. I have satisfied myself by personal inspection of the existing college that that building is quite inadequate to the work which it is intended to perform."

THE American Society of Naturalists held a successful meeting at Chicago at the commencement of this month. There was a discussion on the relation of the Society to other scientific societies, an address by the president, Prof. Sedgwick, NO. I682, VOL. 65$]$ on the modern subjection of science and education to propaganda, dealing largely with attempts to prevent the experimental study of physiology, a lecture by Dr. Howard on international work with beneficial insects, and 244 papers on scientific subjects. The society will meet next winter at Washington, in conjunction with the American Association for the Advancement of Science. A committee was appointed to confer with a similar committee to be appointed by the naturalists of the central and western States in regard to the relations of the two societies. At the meeting to be held next year the president will be Prof. J. McKeen Cattell, and the vice-presidents Messrs. C. D. Wolcott, L. O. Howard and D. P. Penhallow.

We learn from Science that Mr. Andrew Carnegie's gift of ten million dollars for scientific research has been transferred to a corporation to be known as "The Carnegie Institution." The original incorporators include Dr. D. C. Gilman, lately president of Johns Hopkins University, the Hon. Chas. D. Walcott, Director of the U.S. Geological Survey, Dr. John S. Billings, and the Hon. Edward D. White. The objects of the Institution, in addition to the promotion of research, are set forth as follows :-To acquire, hold and convey real estate and other property necessary for the purpose of the Institution and to establish general and specific funds. To conduct, endow and assist investigation in any department of scientific literature or art, and to this end to cooperate with Governments, universities, colleges; technical schools, learned societies and individuals. To appoint committees of experts to direct special lines of research. To publish and distribute documents, to conduct lectures and to hold meetings. To acquire and maintain a library and, in general, to do and perform all things necessary to promote the objects of the Institution.

ON January if Lord Rayleigh opened this season's Friday evening meetings at the Royal Institution with a discourse on the interference of sound. In the course of his remarks he described some of his recent experiments with fog-horns, made for Trinity House. Fog-horns with elliptic cones instead of circular ones were tried, the major axis being about four times longer than the minor one. The experiments showed that the sound was best spread in a horizontal direction when the long axis was exactly vertical. It appears to be doubtful whether the phenomenon of the silent area is really due to interference between waves of sound reaching the spot direct and those reflected from the sea. If the effect were merely due to interference in this way, it ought to be possible to recover the sound by the listener changing his altitude above the sea surface, but Lord Rayleigh has on several occasions tried this on board the Irene and has not recovered the sound. When two or more fog-horns are used at one. station, it sometimes happens that owing to the different sound waves being out of phase they more or less neutralise one another at certain distances, so that one source of sound is sometimes better than several. At the close of Lord Rayleigh's discourse, the Duke of Northumberland, as president of the Institution, unveiled a bust of Sir Frederick Bramwell, formerly honorary secretary of the Institution, and formally presented it to the members on behalf of the managers and their friends as a token of esteem.

THE death is announced of Prof. H. von Ziemssen, professor of pathology and therapeutics in the University of Munich.

COMMISSARY-GENERAL G. D. LARDNER, whose death at the age of eighty-four we regret to see announced, was the eldest son of the renowned Dr. Dionysius Lardner, and, like his father, he did much to encourage the study of astronomy, though his writings and lessons did not reach so large a public. He was a Fellow of the Royal Astronomical Society, and devoted his 